\title{
Proposal of a Planar Directional UWB Antenna for Any Desired Operational Bandwidth
}

\author{
Marco A. Peyrot-Solís, ${ }^{1}$ Giselle M. Galvan-Tejada, ${ }^{2}$ and Hildeberto Jardon-Aguilar ${ }^{2}$ \\ ${ }^{1}$ Mexican Navy Research Institute/CESNAV, 04830 México, DF, Mexico \\ ${ }^{2}$ Department of Electrical Engineering, Center for Research and Advanced Studies of IPN, 07360 México, DF, Mexico
}

Correspondence should be addressed to Marco A. Peyrot-Solís; mapeyrot@yahoo.com

Received 17 February 2014; Revised 12 June 2014; Accepted 17 June 2014; Published 8 July 2014

Academic Editor: Tat Soon Yeo

Copyright (C) 2014 Marco A. Peyrot-Solís et al. This is an open access article distributed under the Creative Commons Attribution License, which permits unrestricted use, distribution, and reproduction in any medium, provided the original work is properly cited.

A novel planar directional UWB antenna is proposed. The antenna design evolves from an oblique elliptic cone antenna by applying the planar-solid correspondence to two axes. Through a simple equation, this antenna can be designed, to operate at a specific lower cutoff frequency with a bandwidth larger than $10 \mathrm{GHz}$ for a reflection coefficient magnitude lower than $-10 \mathrm{~dB}$. This characteristic provides the antenna with a good versatility. The directional radiation pattern has an average gain of $6 \mathrm{dBi}$.

\section{Introduction}

Since 2002 research on UWB antenna has been satisfying the requirements specified by the Federal Communications Commission (FCC), whose efforts have been focused mainly on designs with omnidirectional radiation pattern to improve portable wireless communication systems. However, the necessity of directional UWB antennas is also present for several modern electronic devices such as ground penetration radars, cancer detection, fixed high data wireless local systems, and electronic warfare devices [1-4]. Among the directional UWB antennas reported in the open literature, there are volumetric, planar, and planarized monopoles, and the most representative ones are the ridged horn, the transverse electromagnetic antenna (TEM), and the Vivaldi design, respectively [5-18].

Currently, the research and development of new UWB antennas are result of a critical tradeoff between lower cutoff frequency, radiation pattern, power, gain, size-weight, and cost. Therefore, the operational requirement for a specific device needs a proper UWB antenna with particular characteristics.

The proposed planar directional UWB antenna is derived from a volumetric structure to which the solid-planar correspondence principle is applied. It offers the versatility to have a lower cutoff frequency selected by the designer through a simple equation, and its bandwidth can be wider than $10 \mathrm{GHz}$. Once the dimensions of the antenna have been obtained, the construction is simple and weightless. Thus, the paper is organized as follows. In order to introduce the fundamentals of volumetric and planar designs, some features of the well-known biconical antenna and the solidplanar correspondence principle are described in Section 2; Section 3 presents the design process as an evolution of an omnidirectional conical antenna; in Section 4 details of the design of the proposed antenna are given; the derivation of the equation that relates the lower cutoff frequency and the radiator length is shown in Section 5; the prototypes and obtained results for the input impedance bandwidth and the radiation pattern are described in Section 6; finally, in Section 7 the conclusions are formulated.

\section{From Volumetric to Planar UWB Structures}

2.1. Biconical Antenna. The early studies of wideband antennas considered that to achieve wider bandwidths it was necessary to design volumetric structures based on revolutionsurface radiator elements because they exclude high reactive energy [19]. Harold Wheeler, at the late of the 1950s, postulated two sentences to relate antenna volume and bandwidth [20]: (1) inside a radiansphere, there is a uniformly distributed reactive energy and (2) the unique form to exclude 


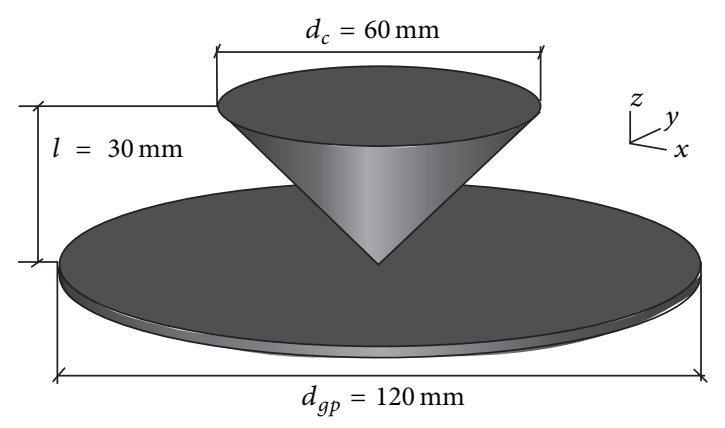

FIgure 1: Conical antenna model with circular aperture.

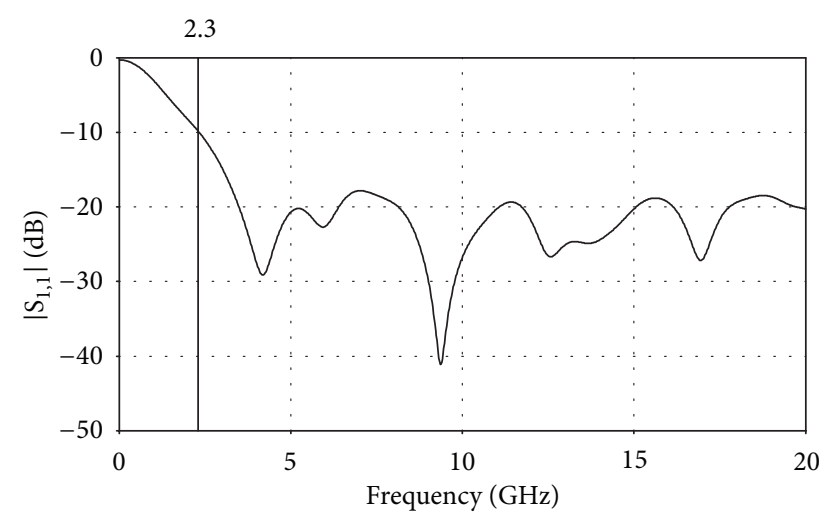

FIGURE 2: Simulated reflection coefficient magnitude of a conical antenna with circular aperture.

that reactive energy is by expanding the antenna dimensions in order to occupy more volume. From the above, the biconical antenna was the first approach in this field [21], and its analysis is based on the transmission line theory due to the fact that it can be seen as a uniformly expanded transmission line.

The classical biconical antenna with a feed point located at the cones ends basically is defined by three parameters (provided it is a symmetrical design, these variables are equal for each cone): height (l), aperture angle $(\alpha)$, and diameter of the circular aperture $\left(d_{c}\right)$. The characteristic impedance relationship of an infinite biconical antenna derived in [22] for an intrinsic impedance of medium $\eta=120 \pi$ (free space) is given by

$$
Z_{c}=120 \ln \left[\cot \left(\frac{\alpha}{4}\right)\right] .
$$

which corresponds to its input impedance, $Z_{\text {in }}$, provided that it is independent of an arbitrary radial distance $r$ [22]. As can be appreciated in (1), the angle $\alpha$ is a key parameter on the performance of this antenna.

2.2. Solid-Planar Correspondence Principle. In order to address the solid-planar correspondence principle, let us first consider a single cylindrical monopole of length $l$ and radio $r_{d}$. If its radio is large, it can be seen as a volumetric structure over which the current is distributed (in other words, on its surface). This element is used as comparison base for other

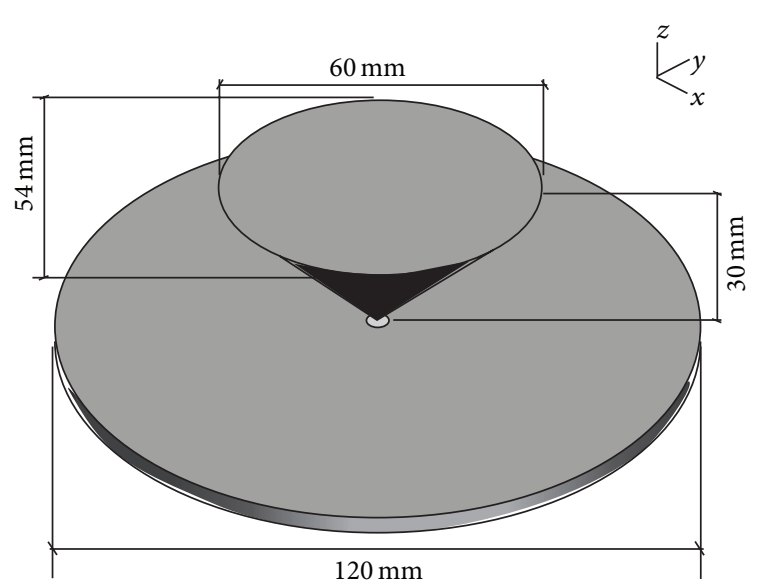

FIgURE 3: Conical antenna model with elliptical aperture.

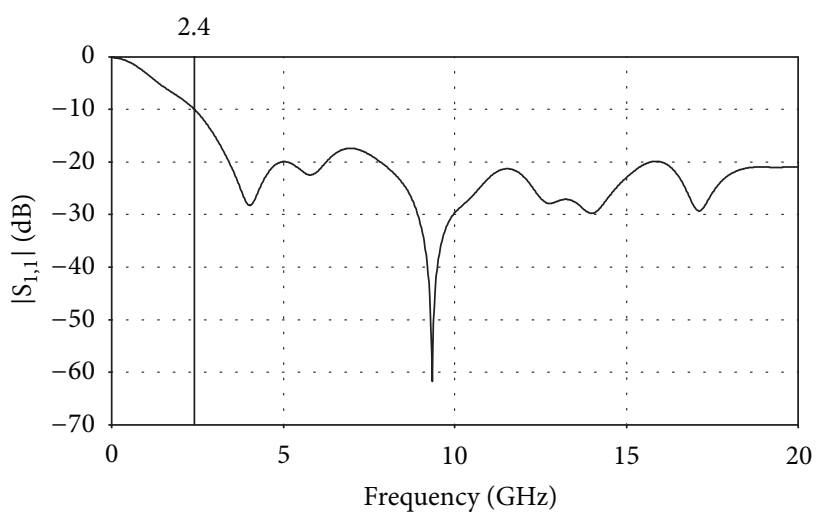

FIGURE 4: Reflection coefficient magnitude of a conical antenna with elliptical aperture.

planar structures, in such a way that their areas are made equal (i.e., $2 \pi r_{d} l=A$ with $A$ the area of the planar antenna) and it stated a relationship between $r_{d}$ and the dimensions of the radiator on question. Please observe that the radiator height is made equal to the cylinder length $l$, which gives a significant importance to this parameter.

Thus, the solid-planar correspondence principle simply states that, for any surface-revolution structure, there exists its counterpart planar antenna [19]. Therefore, it is possible to achieve an equivalent performance of a volumetric radiator structure through its corresponding planar version.

From the above, the older idea that "fat" structures were necessary to achieve wider bandwidths was removed and a boom on planar designs for UWB antennas marked a new era during the 1990s decade.

\section{Design Process}

The design process takes as a basis a single conical antenna on a large flat ground plane and whose input impedance is one-half of the biconical structure [22]:

$$
Z_{\text {in }}=60 \ln \left[\cot \left(\frac{\alpha}{4}\right)\right] .
$$




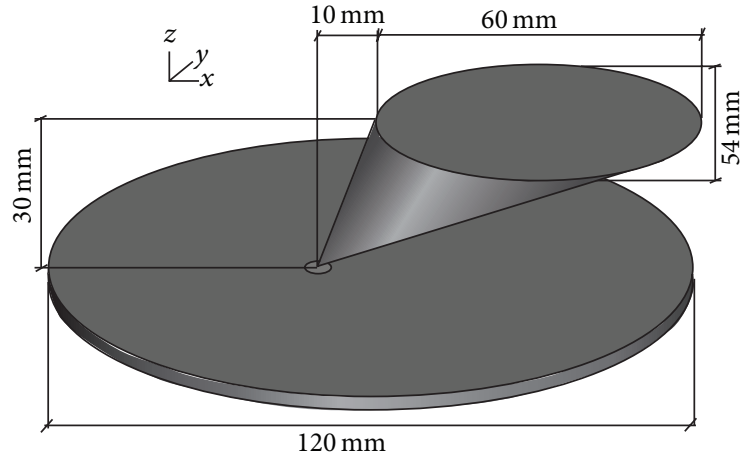

Figure 5: Conical antenna with elliptical aperture displaced of $40 \mathrm{~mm}$.

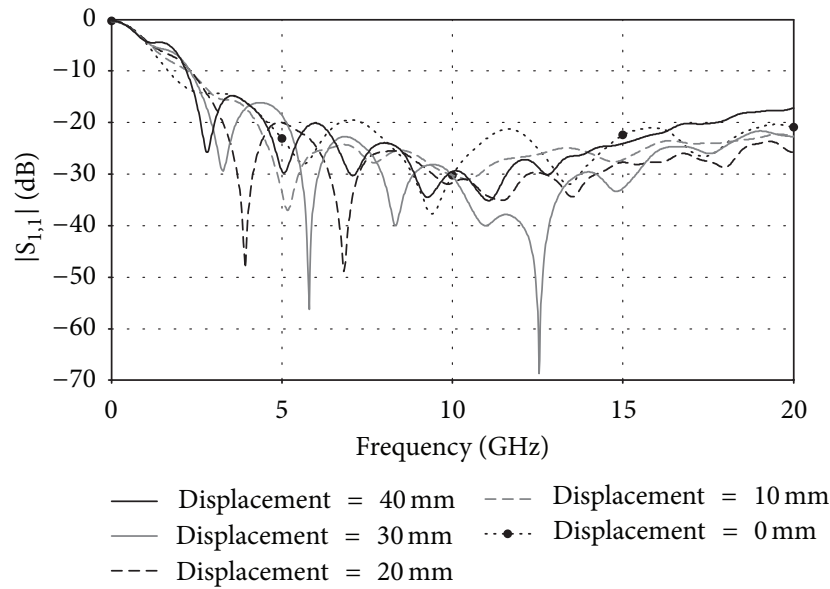

FIGURE 6: Reflection coefficient magnitude of a conical antenna with elliptical aperture displaced from 0 to $40 \mathrm{~mm}$.

By following results presented in [23], it is found that a value of $\alpha=90^{\circ}$ provides very low variations on the reactive part of the conical antenna impedance over a very wide range of frequencies and radiator lengths. Therefore, for $\alpha=90^{\circ}$, $d_{c}=2 l$ and $Z_{\text {in }}=52.8 \Omega \approx 50 \Omega$. In order to fade the imaginary part of the input impedance to zero, the length of a monopole can be approached to $0.24 \lambda$ as suggested in [22] For a resonant frequency of $2.4 \mathrm{GHz}$ and by taking the cone height as the monopole length, $l=30 \mathrm{~mm}$ and $d_{c}=60 \mathrm{~mm}$. Figure 1 shows this basic structure for a circular ground plane with diameter $d_{\mathrm{gp}}=120 \mathrm{~mm}$, which is approximately equal to $\lambda$.

This antenna was simulated in the CST Microwave Studio software [24] (in fact all simulation results presented through this paper were obtained with this tool). The corresponding result for the reflection coefficient magnitude is shown in Figure 2. From this figure it can be seen that the lower cutoff frequency is $2.3 \mathrm{GHz}$ and the bandwidth is wider than $17 \mathrm{GHz}$. In this antenna the radiation pattern is omnidirectional.

In order to convert the omnidirectional pattern of the conical antenna into a directional one, the first approach is to change the circular aperture of the cone by an elliptical one with an excentricity of 0.44 but maintaining the circular

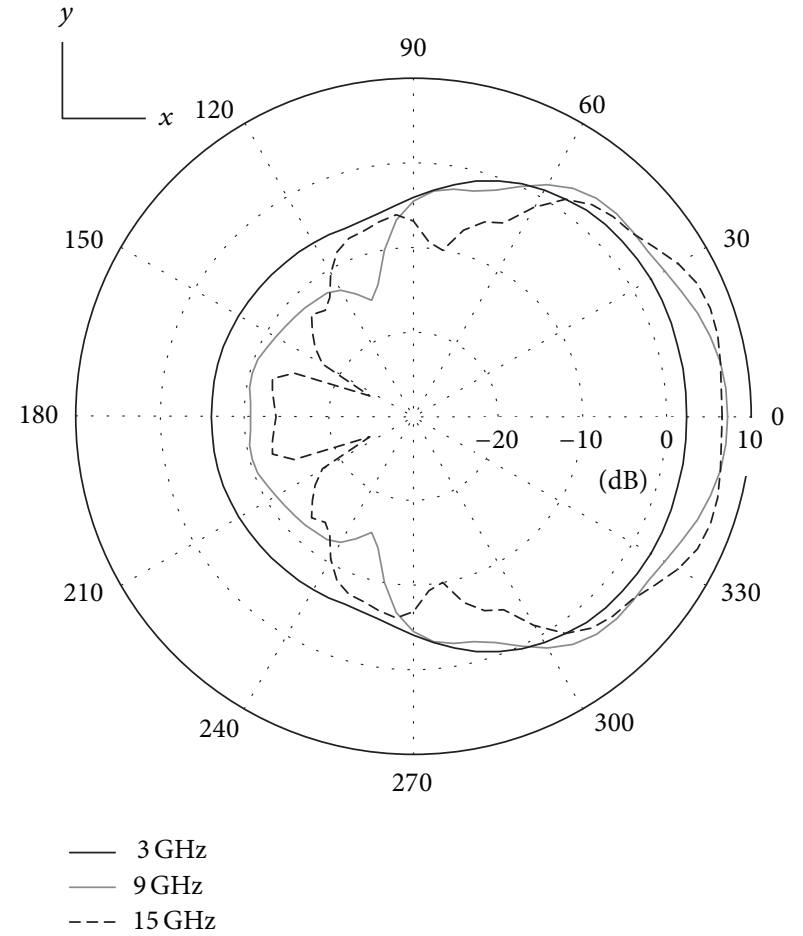

FIGURE 7: Radiation pattern of a conical antenna with elliptical aperture displaced of $40 \mathrm{~mm}$ in the $x y$ plane.

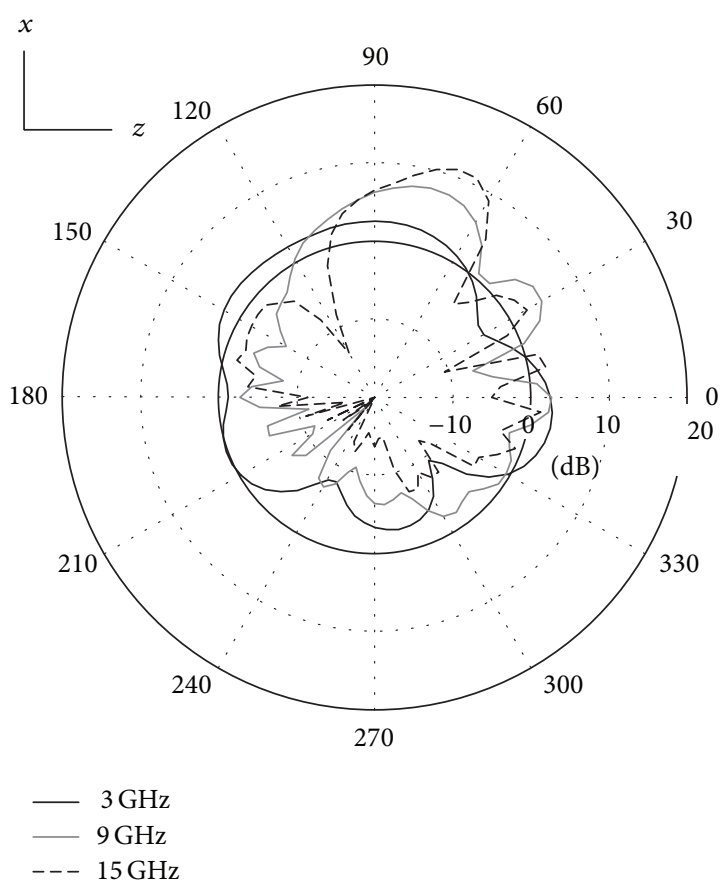

FIgURE 8: Radiation pattern of a conical antenna with elliptical aperture displaced of $40 \mathrm{~mm}$ in the $x z$ plane.

ground plane (Figure 3 shows the modifications to an elliptical cone where the minor axis is $54 \mathrm{~mm}$ ). The elliptical conical antenna provides a similar reflection coefficient magnitude (see Figure 4 ) with a lightly directional radiation pattern. 


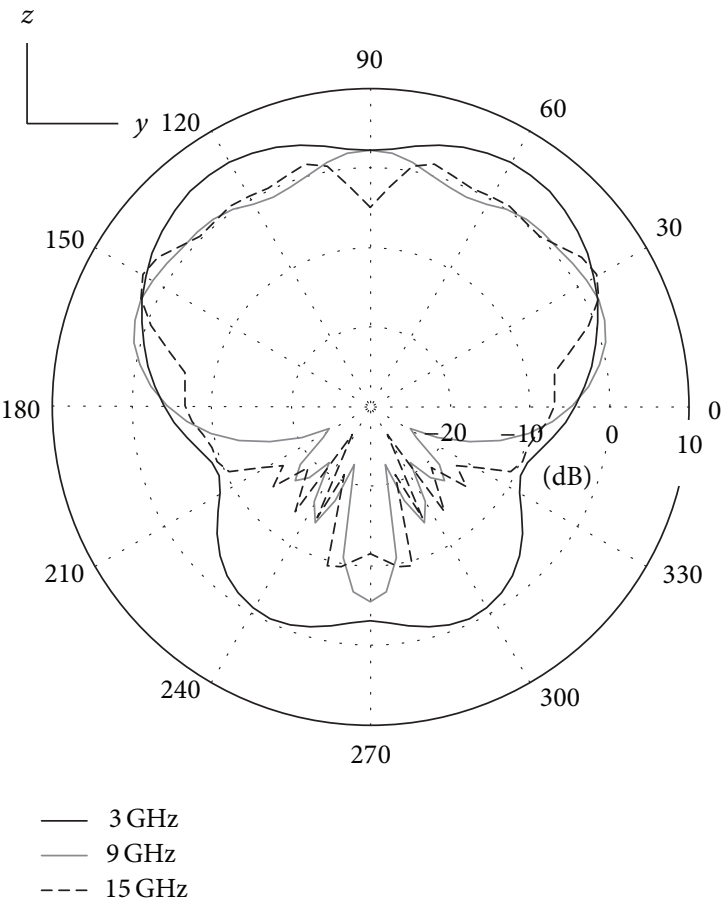

FIGURE 9: Radiation pattern of a conical antenna with elliptical aperture displaced of $40 \mathrm{~mm}$ in the $y z$ plane.

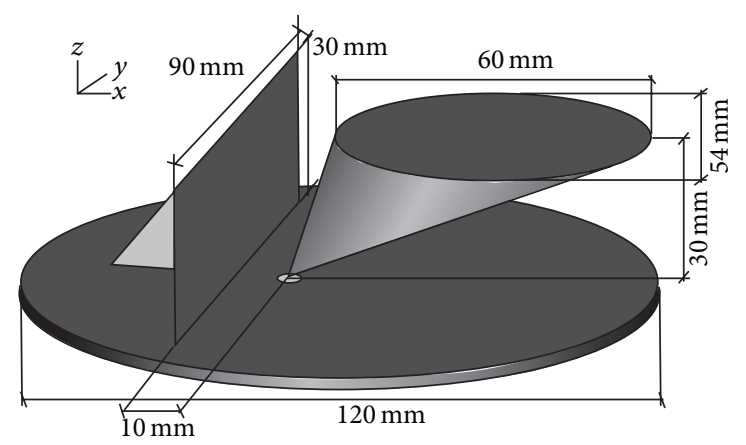

Figure 10: Conical antenna with elliptical aperture and reflector.

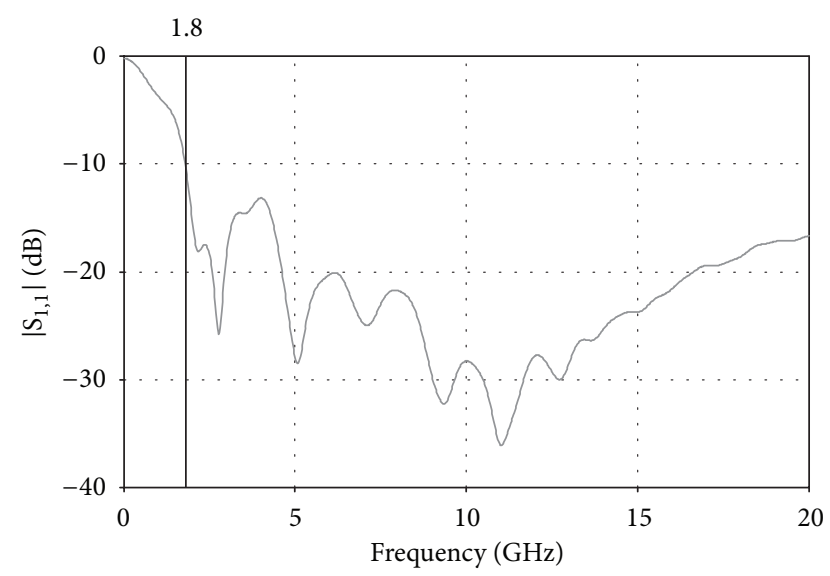

FIGURE 11: Reflection coefficient magnitude of a conical antenna with elliptical aperture and reflector.

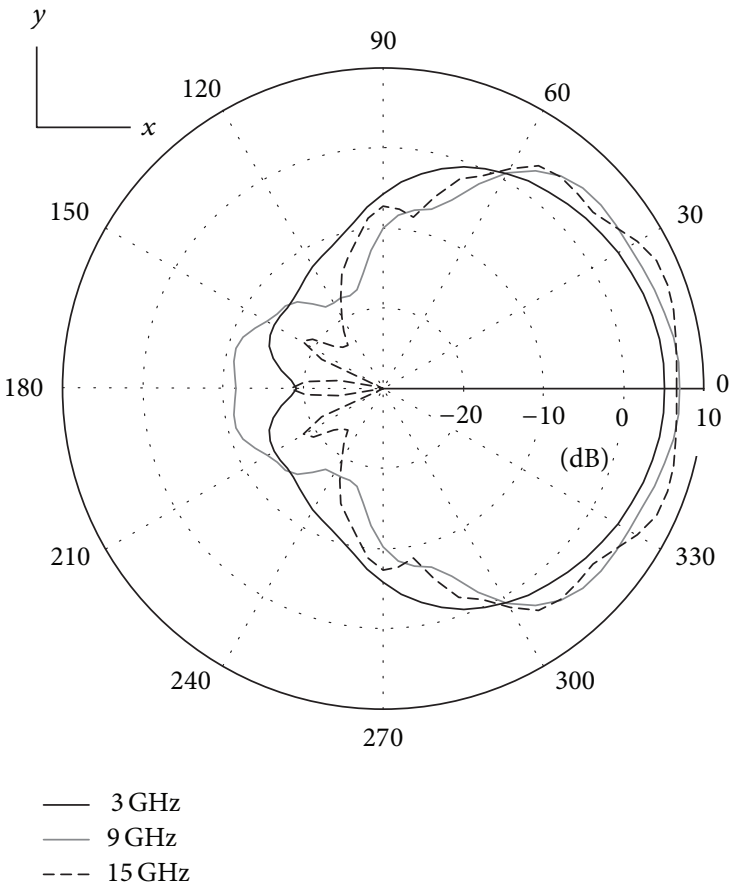

FIGURE 12: Radiation pattern of a conical antenna with elliptical aperture and reflector in the $x y$ plane.

It can be observed from Figure 4 that, for $\left|S_{1,1}\right| \leq-10 \mathrm{~dB}$, the bandwidth is wider than $17 \mathrm{GHz}$, and the lower cutoff frequency is $2.4 \mathrm{GHz}$.

The next step used to provide directivity was to slant the radiator [25], as shown in Figure 5. The slant angle applied to the radiator can be mapped to a displacement relative to the vertical axis of the cone. Thus, the simulated reflection coefficient magnitude for several displacements is represented in Figure 6. From this figure, it can be concluded that this displacement does not affect significantly the impedance bandwidth but does increase the pattern directivity. In fact the antenna gain goes from $2.5 \mathrm{dBi}$ to $7.9 \mathrm{dBi}$ for the whole bandwidth in the $x y$ plane. Figures 7,8 , and 9 show the simulated radiation pattern for the $x y, x z$, and $y z$ planes, respectively.

With the aim of increasing the gain and decreasing the back lobe at low frequencies, a reflector was introduced as depicted in Figure 10. A central aspect in this approach is the location of the reflector relative to the feed point. This design detail was addressed through a tuning process taking into account the impedance matching bandwidth, after which and for the current dimensions of the antenna we found that the best distance between the reflector and the feed point was $10 \mathrm{~mm}$. The simulated reflection coefficient magnitude is shown in Figure 11.

In Figures 12, 13, and 14 the simulated radiation pattern for the $x y, x z$, and $y z$ planes, respectively, can be shown for the conical antenna with elliptical aperture and reflector.

The effect of the reflector on both lower and upper cutoff frequencies can be analyzed in Figure 11. The former frequency changes from $2.4 \mathrm{GHz}$ to $1.8 \mathrm{GHz}$ and the upper 

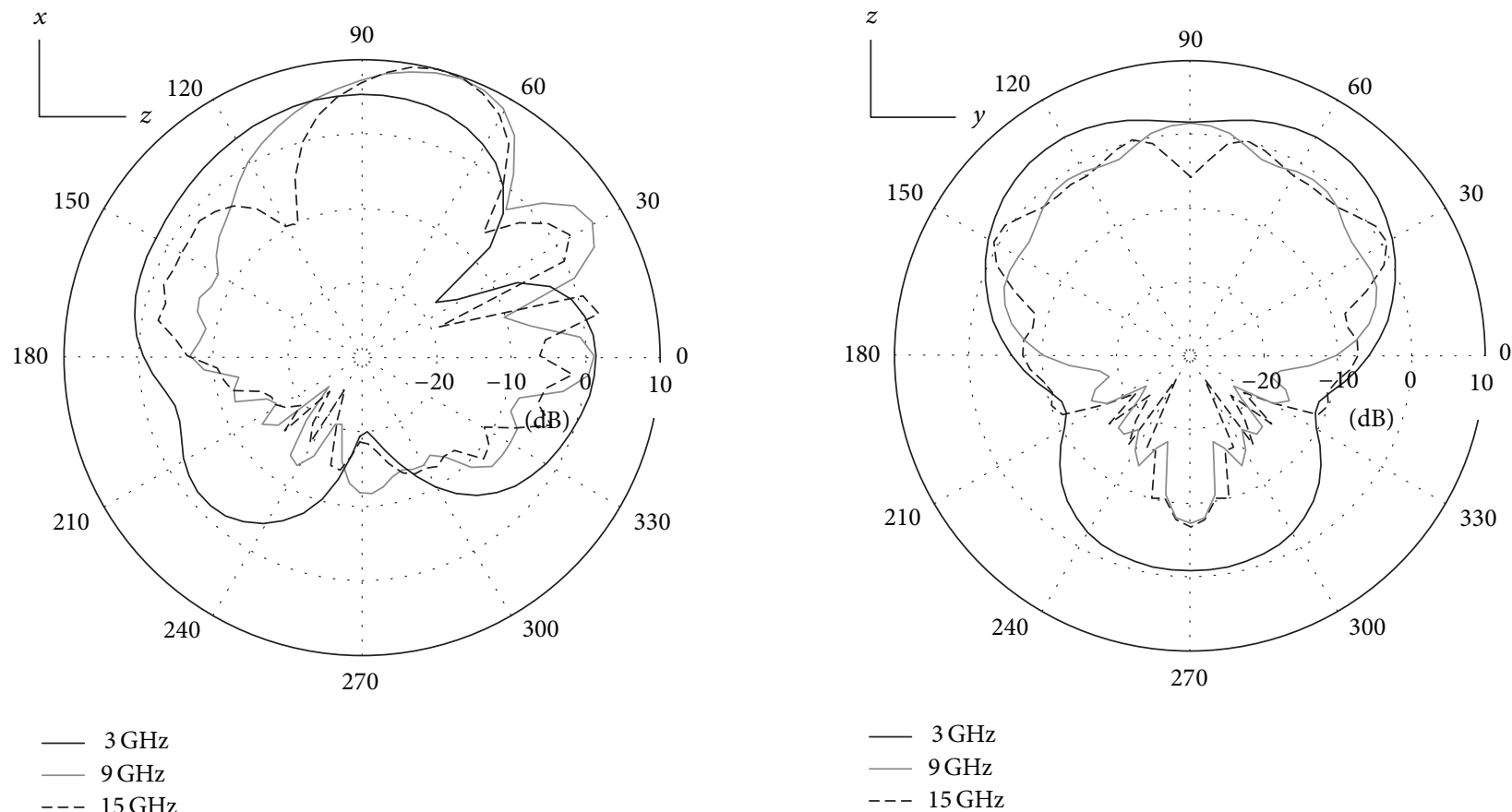

FIGURE 13: Radiation pattern of a conical antenna with elliptical aperture and reflector in the $x z$ plane.

cutoff frequency continues to be higher than $20 \mathrm{GHz}$. From Figure 12 it is found that the gain goes from 5 to $7.9 \mathrm{dBi}$. This behavior allows us to assert that the main effect of the inserted reflector is on the lower cutoff frequency and on the gain at low frequencies. As regards the effect of the reflector on the back lobes, Figure 12 illustrates an improvement of the main lobe stability. It is worth mentioning here that the dimensions of the reflector were determined by a parametric study. Although these dimensions could affect the antenna performance, we do not explore to vary them at all and it could be matter of a future correspondence.

To evolve the antenna of Figure 10 to a directional and planar one, the elliptical aperture is maintained and the planar-solid correspondence (see Section 2) in two axes is applied, as presented in Figure 15 (provided that we still preserve the elliptical aperture structure, let us call this design semiplanar conical antenna) and whose results for the simulated reflection coefficient magnitude are shown in Figure 16.

In Figure 16 it can be seen that the lower cutoff frequency has been shifted approximately to $0.3 \mathrm{GHz}$ (from 1.8 to $2.1 \mathrm{GHz}$ ), but the upper cutoff frequency is still larger than $20 \mathrm{GHz}$

In Figures 17, 18, and 19 the simulated radiation pattern for the $x y, x z$, and $y z$ planes, respectively, is shown for the semiplanar conical antenna with elliptical aperture and reflector. It is observed that the main lobe stability is affected at high frequencies.

Now, by applying the solid-planar correspondence principle to the elliptical aperture of the radiator of Figure 15, we found through simulations that it does not affect substantially

FIGURE 14: Radiation pattern of a conical antenna with elliptical aperture and reflector in the $y z$ plane.

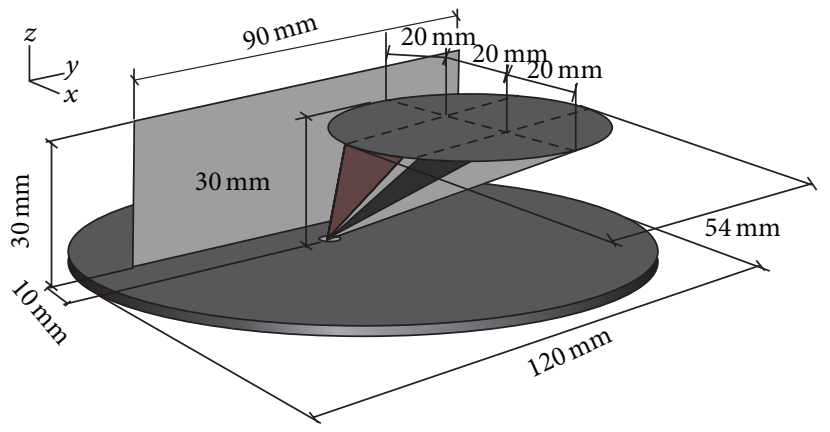

FIGURE 15: Semiplanar conical antenna with elliptical aperture and reflector.

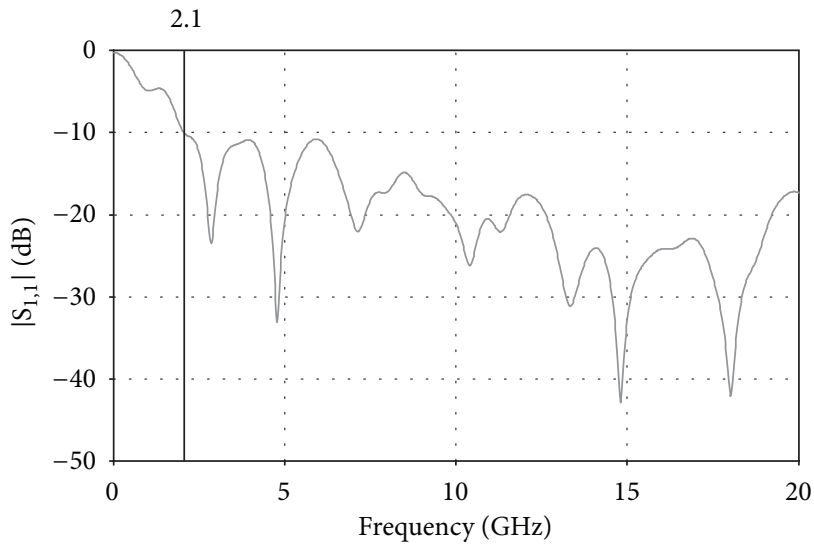

FIGURE 16: Reflection coefficient magnitude of a semiplanar conical antenna with elliptical aperture and reflector. 


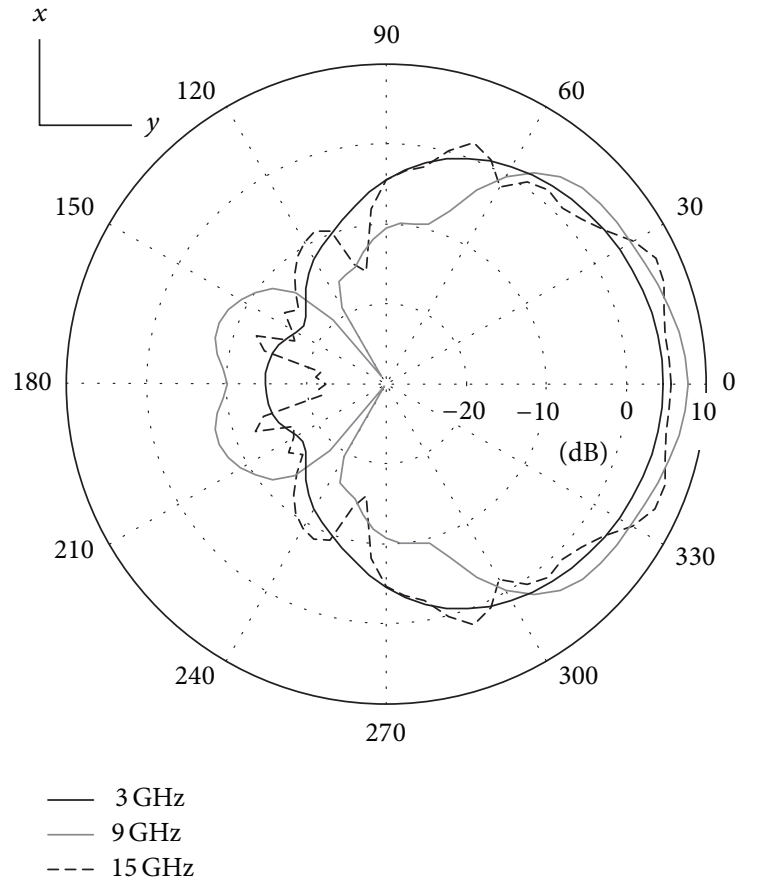

FIGURE 17: Radiation pattern of a semiplanar conical antenna with elliptical aperture and reflector in the $x y$ plane.

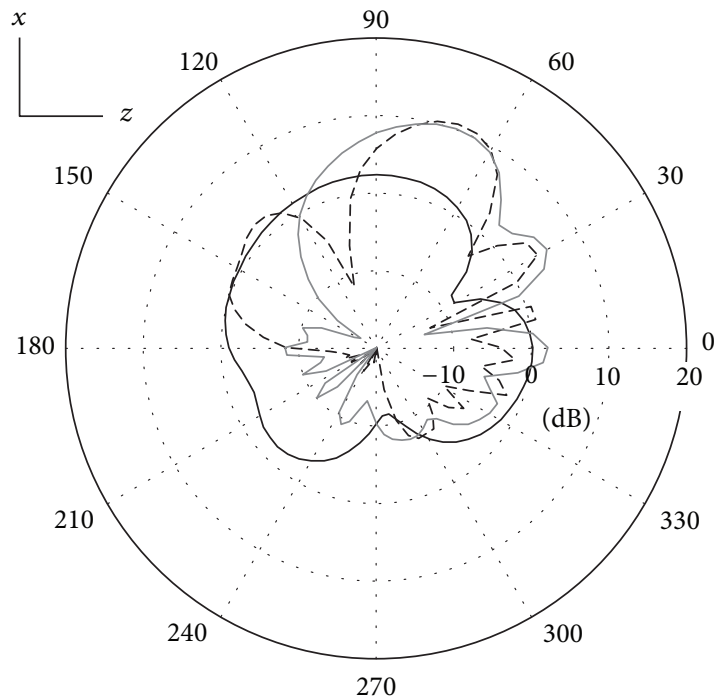

$$
\begin{aligned}
& -3 \mathrm{GHz} \\
& -9 \mathrm{GHz} \\
& ---15 \mathrm{GHz}
\end{aligned}
$$

FIGURE 18: Radiation pattern of a semiplanar conical antenna with elliptical aperture and reflector in the $x z$ plane.

both the impedance bandwidth and the gain, and as a consequence it can be eliminated, which allows us to have a fully planar directional antenna.

The effect of the evolution from volumetric to planar antenna modifying the impedance matching variables properly provides an increase of $0.3 \mathrm{GHz}$ in the lower cutoff

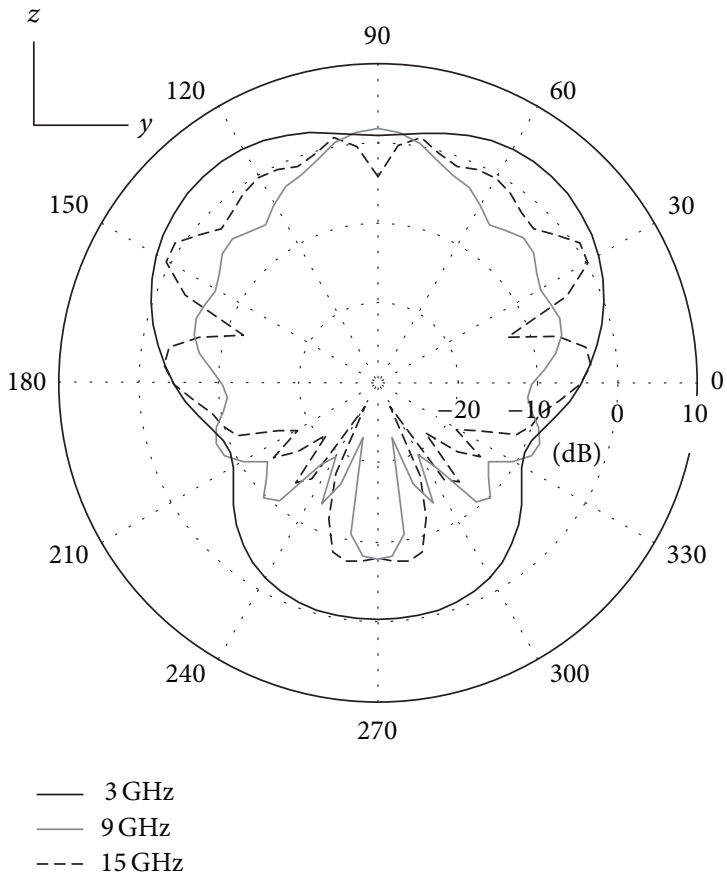

FIGURE 19: Radiation pattern of a semiplanar conical antenna with elliptical aperture and reflector in the $y z$ plane.

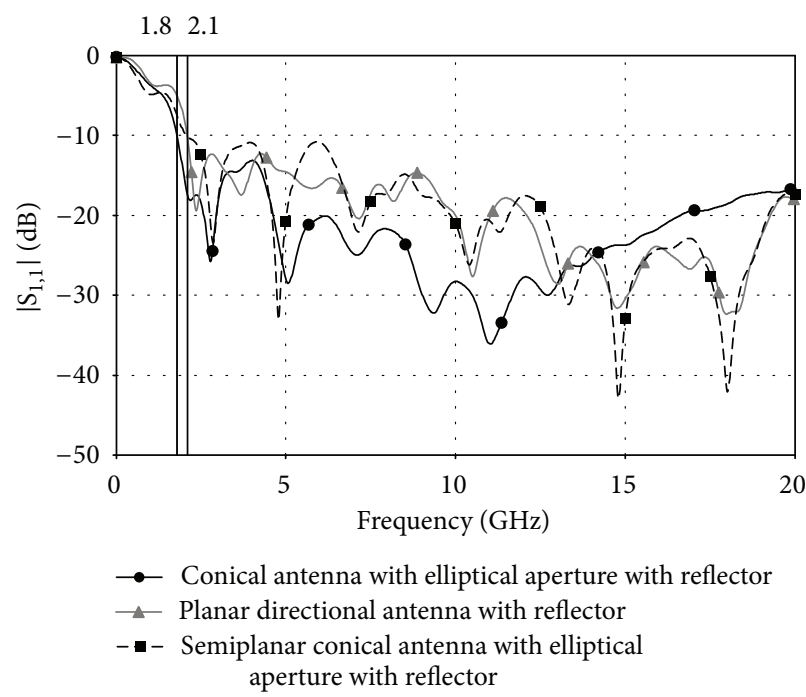

FIgURE 20: Reflection coefficient magnitude from volumetric to planar antenna evolution.

frequency as can be seen in Figure 20, where the plots of the magnitude of the reflection coefficients of Figures 11 and 16 are included for comparison purposes. Additionally, we analyze possible impact on the radiation pattern as well. Thus, in Table 1 the main properties of the directional radiation patterns of the antenna models created during the evolution from volumetric to planar structure are shown. As can be seen most of values do not vary significantly during the entire design process; however, a reduction of the $3 \mathrm{~dB}$ beamwidth 


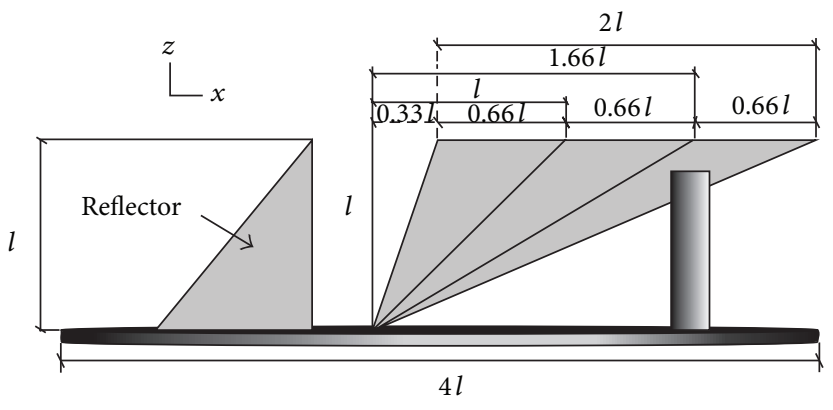

(a)

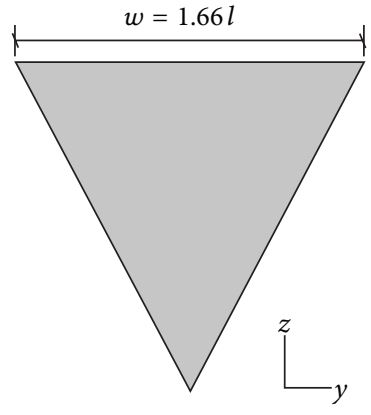

(b)

FIGURE 21: Lateral view of the proposed planar directional UWB antenna (a) and front view of the isosceles triangle (b).

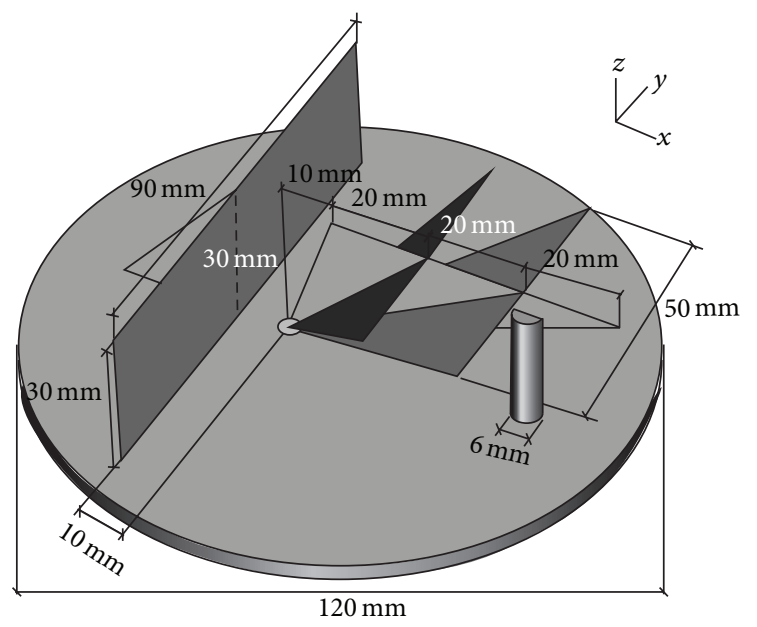

Figure 22: Proposed planar directional UWB antenna for a lower cutoff frequency of $2 \mathrm{GHz}$.

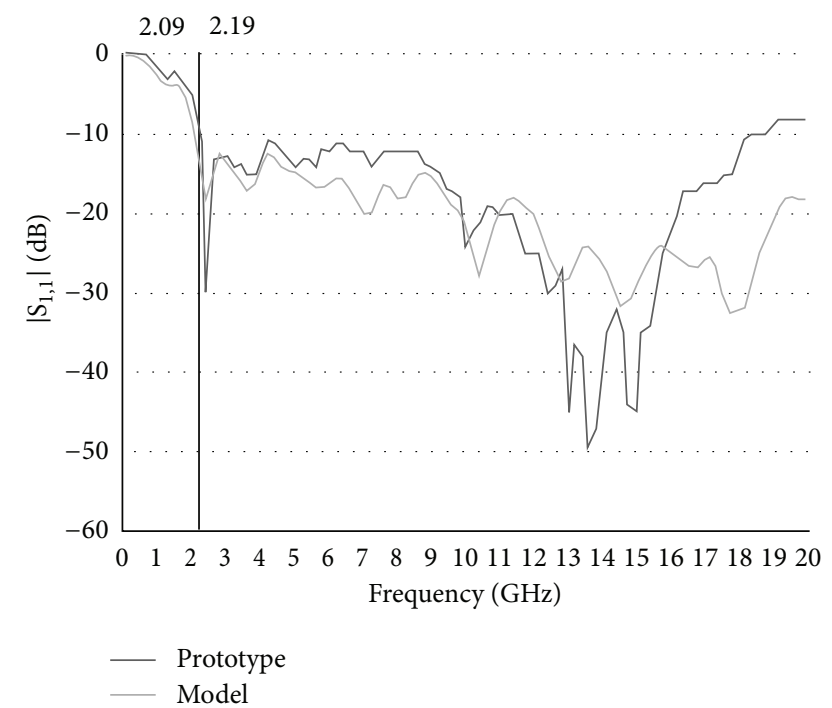

FIGURE 23: Simulated and measured reflection coefficient magnitude of the proposed planar directional UWB antenna.
TABLE 1: Comparison of some parameters of directional antennas.

\begin{tabular}{lccc}
\hline $\begin{array}{l}\text { Frequency } \\
(\mathrm{GHz})\end{array}$ & $\begin{array}{c}\text { Boresight gain } \\
(\mathrm{dB})\end{array}$ & $\begin{array}{c}3 \mathrm{~dB} \text { beamwidth } \\
\text { (degree) }\end{array}$ & $\begin{array}{c}\text { Front-to- } \\
\text { back ratio } \\
(\mathrm{dB})\end{array}$ \\
\hline 3 & Conical antenna with elliptical aperture and reflector \\
3 & 5.1 & 98.3 & -19.4 \\
6 & 8.0 & 66.8 & -14.9 \\
9 & 7.0 & 103.6 & -18.0 \\
12 & 7.2 & 96.5 & -20.2 \\
15 & 7.8 & 73.9 & -26.0 \\
18 & 6.8 & 88.0 & -18.0 \\
\hline Semiplanar conical antenna with elliptical aperture and reflector \\
3 & 4.6 & 114.5 & -19.5 \\
6 & 8.5 & 50.7 & -28.0 \\
9 & 7.7 & 87.9 & -15.5 \\
12 & 6.6 & 90.5 & -15.8 \\
15 & 7.1 & 66.4 & -17.0 \\
18 & 5.8 & 85.0 & -15.0 \\
\hline & Planar directional antenna & \\
3 & 5.3 & 98.6 & -14.9 \\
6 & 7.6 & 65.4 & -18.0 \\
9 & 7.8 & 66.1 & -16.5 \\
12 & 8.3 & 42.7 & -18.0 \\
15 & 6.6 & 66.9 & -16.5 \\
18 & 6.4 & 70.0 & -15.5 \\
\hline & & &
\end{tabular}

at intermediate frequencies (9 and $12 \mathrm{GHz}$ ) for the planar directional antenna is appreciated.

\section{Design of the Proposed Antenna}

The final shape of the evolved directional and planar antenna derived from the circular cone based structure is shown in Figure 21, and it is formed by three triangular plates of brass, two of them are isosceles, and the other one is scalene. The scalene triangle is in the desired main lobe direction, and the isosceles triangles are in a perpendicular position. This radiator is on a circular ground plane with the feed point displaced from its center. It is worth noting that the best obtained relationship of $w=1.66 l$ was determined by simulations. 


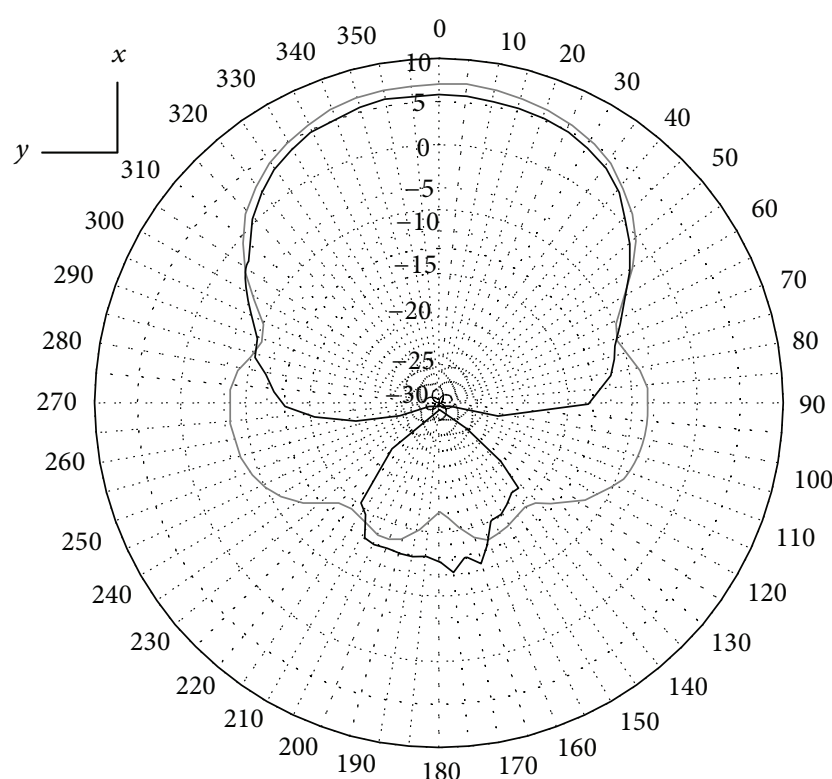

- Measured gain $(\mathrm{dB})$

Simulated gain $(\mathrm{dB})$

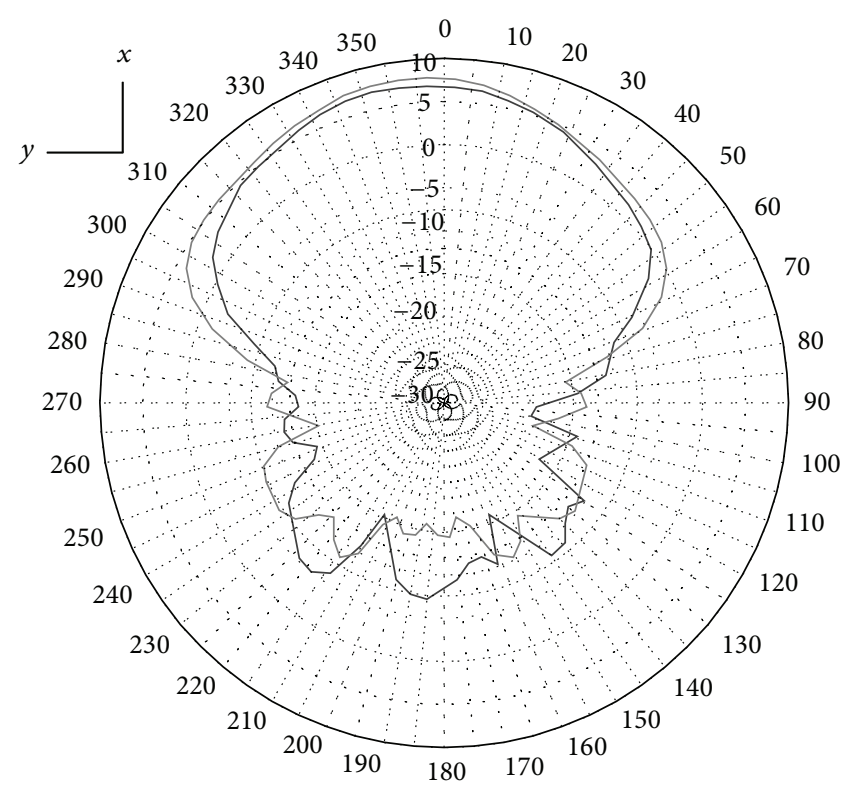

- Measured gain $(\mathrm{dB})$

_ Simulated gain $(\mathrm{dB})$

(a)

(b)

FIgURE 24: Measured and simulated radiation pattern at $5 \mathrm{GHz}$ (a) and $10 \mathrm{GHz}$ (b) of the first proposed planar directional UWB antenna prototype.

Figure 22 shows the geometry and dimensions of this proposed structural antenna, which are obtained by following the design of the conical antenna for an input impedance of $50 \Omega$.

Thus, once the radiator is totally planar, it can be possible to find a design equation for a desired lower cutoff frequency by applying the theory that a planar monopole antenna can be seen like a cylindrical monopole with an effective diameter very wide. In the next section, this design equation for the proposed antenna will be derived. To evaluate the feasibility of the design equation, two antennas will be designed, constructed, and measured. The first prototype will preserve the antenna dimensions shown in Figure 9, whereas the second one will be designed to fulfill the lower cutoff frequency of the UWB bandwidth [26].

\section{Lower Cutoff Frequency}

Based on the theory that a planar monopole antenna can be seen like a cylindrical monopole with an effective diameter very wide and on which the planar-solid correspondence principle has been applied, the lower cutoff frequency can be obtained through the equation to find the monopole length for a real input impedance given by [19]

$$
l=(0.24) \lambda F,
$$

where $F$ is a term known as length-ratio equivalent. This dimensionless parameter can have a value from 0.86 for a square planar monopole to 0.99 for a thin wire monopole [27]. The term $F$ is used to determine an equivalent area between a cylindrical monopole and a planar monopole radiator [28] and is expressed by

$$
F=\frac{l}{r_{d}+l}
$$

where $r_{d}$ is the radius of the cylindrical monopole in $\mathrm{mm}$. The design procedure consists in making the proposed radiator area equal (in this case, let us assume that each triangle represents $1 / 3$ of the total area of the radiator; thus the radiator area is the contribution of areas given by two isosceles triangles and one scalene triangle) with the cylindrical monopole area (given by $2 \pi r_{d} l$ ). Therefore, for $w$ and $L$, the width of the isosceles and scalene triangles, respectively, is

$$
2 \pi r_{d} l=\frac{1}{3}\left(\frac{w l \sqrt{2}}{2}\right)+\frac{1}{3}\left(\frac{w \sqrt{l^{2}+w^{2}}}{2}\right)+\frac{1}{3}\left(\frac{l L}{2}\right) .
$$

Provided that $L=2$ land after replacing it and $w=1.66 l$ in (5) and through a simple mathematical manipulation, it is possible to find that

$$
r_{d}=0.2 l
$$

Replacing (6) in (4) and in turn in (3), we found the relationship between the radiator height and the desired lower cutoff frequency for the proposed planar directional UWB antenna as

$$
f_{L}=\frac{60}{l}
$$




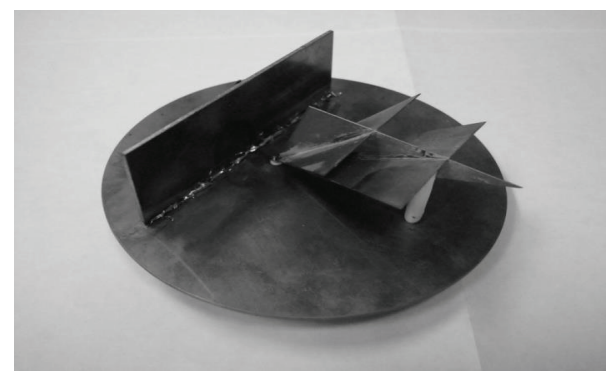

FIgURE 25: Proposed planar directional UWB antenna prototype.

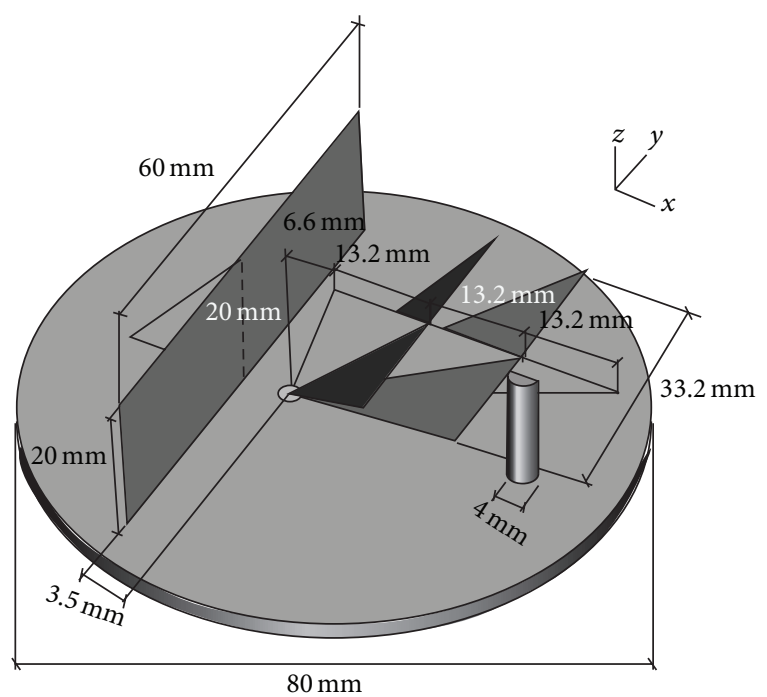

Figure 26: Dimensions of the planar directional UWB antenna for a lower cutoff frequency of $3 \mathrm{GHz}$.

with $f_{L}$ the lower cutoff frequency in $\mathrm{GHz}$ and $l$ in mm. Please note that the factor of 60 comes from a units' conversion such that all dimensions are in $\mathrm{mm}$ and the frequency is in $\mathrm{GHz}$.

\section{Prototypes of the Antenna}

The design equation that relates the lower cutoff frequency with the radiator length of the directional and planar UWB antenna evolved from an omnidirectional conical structure is validated through the development of two prototypes. In order to evaluate the simulated lower cutoff frequency obtained for the directional conical antenna model shown in Figure 21, the first prototype is designed for a lower cutoff frequency of $2 \mathrm{GHz}$. On the other hand, the second one is for a lower cutoff frequency of $3 \mathrm{GHz}$ with the objective of designing an antenna which fulfills the requirements given for UWB antennas imposed by the FCC [26].

In order to validate these designs in terms of impedance matching and radiation pattern, both prototypes were evaluated, respectively, by using an Agilent NPA Series network analyzer E8362B calibrated to a $50 \Omega$ SMA connector, and by making up a semiclosed structure (except by the ceiling) of electromagnetic absorbers ETS-Lindgren model FL-4500CL to measure their radiation patterns. It is worth noting that

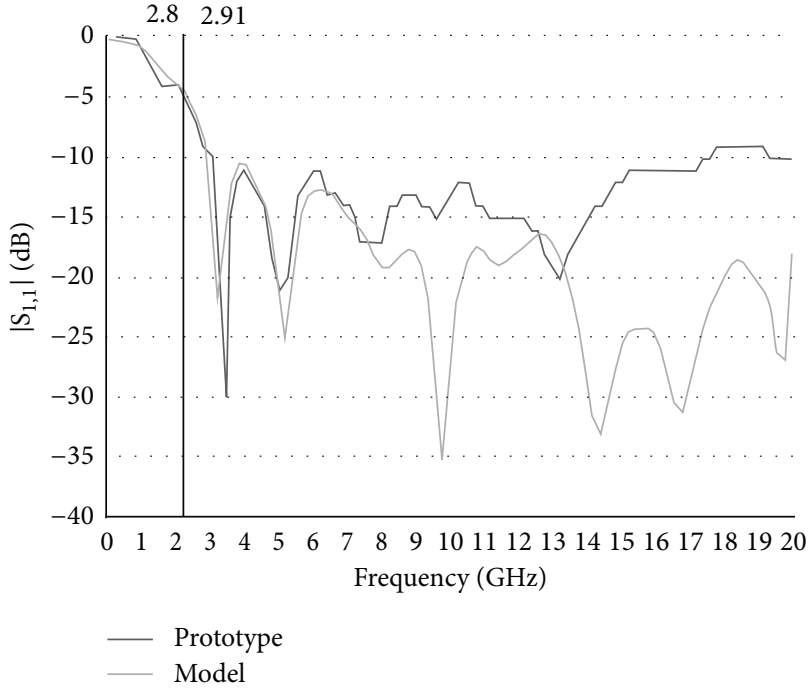

FIGURE 27: Simulated and measured reflection coefficient magnitude of the proposed planar directional UWB antenna for a lower cutoff frequency of $3 \mathrm{GHz}$.

in this last measurement the distance from both transmit and receive antennas to the absorbers was at least ten times the wavelength of the lower frequency. Both prototypes were used as transmit antenna and the receive antenna was a standard double crest horn antenna [1]. The obtained results have an error of $1 \mathrm{~dB}$ lower than those achieved in an open area calibration test site.

6.1. First Prototype. Using (6) and considering that the design comes from a conical antenna, for a lower cutoff frequency of $2 \mathrm{GHz}$, its dimensions appeared as shown in Figure 22 . Note that the antenna dimensions are a function of the "cone" height (i.e., the vertical side of the scalene triangle $l$ ).

The simulated and measured reflection coefficient magnitude for the model and prototype can be seen in Figure 23. The simulated and the measured lower cutoff frequency (2.09 GHz and $2.19 \mathrm{GHz}$, resp.) have a difference of only $0.1 \mathrm{GHz}$, with a measured bandwidth of $16.2 \mathrm{GHz}$. These results provide a good agreement with the initial value applied to (7) to obtain the radiator length. Regarding the radiation pattern characteristics, the behavior of the simulated and measured radiation pattern for this model and prototype shows a good agreement and indicates an improvement on the main lobe stability once the elliptical aperture was removed (see Figure 24).

In general, although we observe more variations of the radiation pattern as a function of frequency (particularly when it is increased), in all cases a good agreement between simulated and measured results is achieved. Due to space limitations, only the measured and simulated radiation pattern at 5 and $10 \mathrm{GHz}$ are depicted in Figure 24. As can be appreciated, the measured gain is maintained around $6 \mathrm{dBi}$.

This antenna was built in a brass sheet and it is depicted in Figure 25. The feeding point uses a $50 \Omega$ SMA connector of moderate quality (guaranteed up to $12 \mathrm{GHz}$ ). The reason 


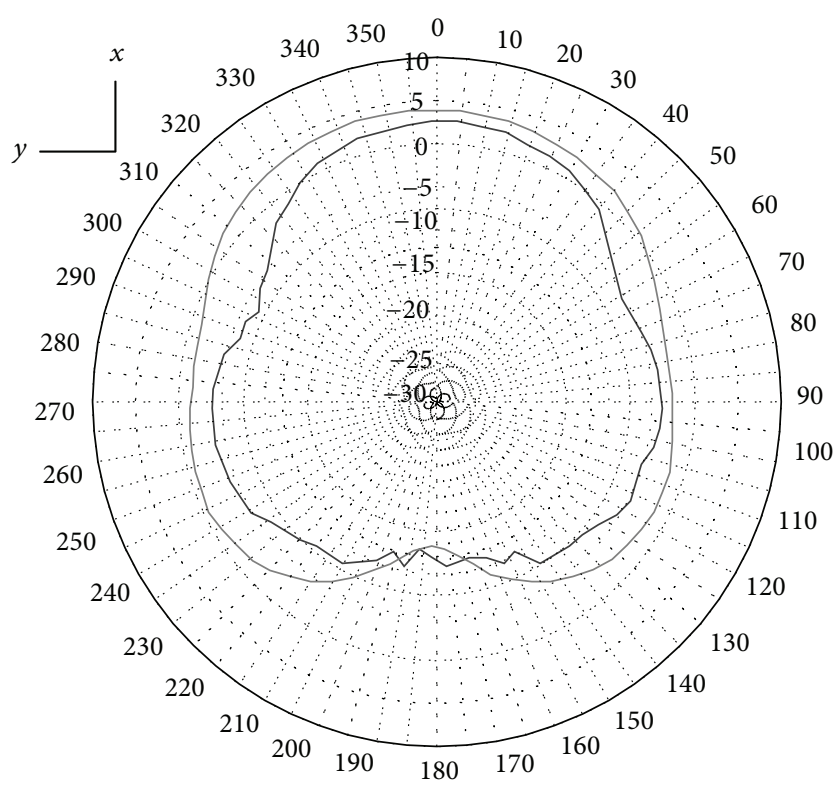

- Measured gain $(\mathrm{dB})$

_ Simulated gain $(\mathrm{dB})$

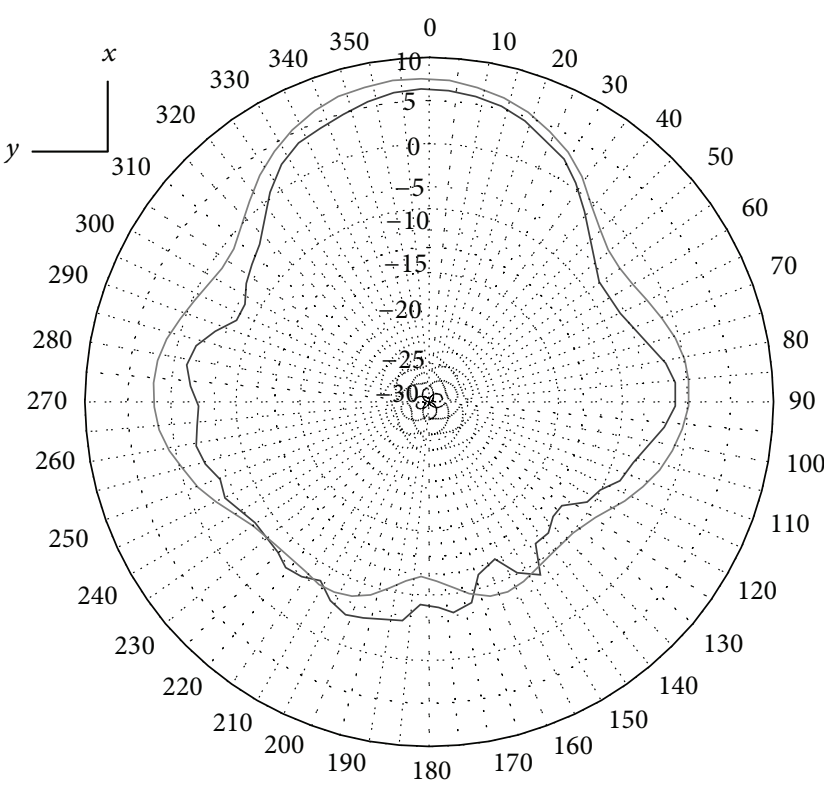

- Measured gain $(\mathrm{dB})$

_ Simulated gain $(\mathrm{dB})$

(a)

(b)

FIGURE 28: Measured and simulated radiation pattern at $5 \mathrm{GHz}(\mathrm{a})$ and $10 \mathrm{GHz}$ (b) of the second proposed planar directional UWB antenna.

for a not good agreement after $13 \mathrm{GHz}$ for the simulated and measured reflection coefficient magnitudes is precisely this $50 \Omega$ SMA connector of moderate quality. Finally, for mechanical robustness a $6 \mathrm{~mm}$ Teflon post was used as support.

6.2. Second Prototype. This prototype is designed to operate from $3.1 \mathrm{GHz}$ as authorized by the FCC [26] for UWB communications (let us call it "FCC prototype"). Then, by taking $3 \mathrm{GHz}$ as desired lower cutoff frequency and by using (7) the radiator height, $l=20 \mathrm{~mm}$. By following the geometry of the antenna in Figures 12 and 13, the dimensions of the design for $f_{L}=3 \mathrm{GHzappear}$ as can be seen in Figure 26. As in the previous case, we used for this second prototype the same material and SMA connector. The photograph of this FCC prototype is not shown due to space limitation.

Results of simulations and measurement for the reflection coefficient magnitude of the model of Figure 26 are shown in Figure 27, whereas the simulated and measured radiation pattern for the second prototype are shown in Figure 28. From these results, we observe a simulated lower cutoff frequency of $2.91 \mathrm{GHz}$, which provides a good agreement with the one taken as design basis. The bandwidth is wider than $17 \mathrm{GHz}$. By comparing $f_{L}$ obtained both by simulations and by measurements against the design value of $3 \mathrm{GHz}$, we find a difference of $0.1 \mathrm{GHz}$ and $0.2 \mathrm{GHz}$, respectively. This result allows us to state that (7) is a good mean to determine the radiator length from the lower cutoff frequency for antennas like the one shown in Figure 21. Regarding the radiation characteristics, there is an acceptable agreement between measured and simulated radiation pattern as can be appreciated in Figure 28. The measured gain in the main lobe is about $2 \mathrm{dBi}$ less than the simulated one.

Finally, in order to compare the antenna gain as a function of frequency, the tabulated simulated and measured gain of both prototypes are shown in Figure 29. The same trend on the variation of this antenna parameter is observed for each prototype, in such a way that the differences between measured and simulated gains are almost preserved through all the frequencies.

\section{Conclusions}

The design of directional UWB antennas has recently been an area of interest for research. The search of this type of devices motivated us to explore new design possibilities under the well-known constraints that UWB antennas have. Thus, based on the solid-planar correspondence principle, a process to obtain a planar directional UWB antenna from a volumetric conic antenna with a slant angle was gradually developed in this paper. Through this process a novel planar directional UWB antenna was achieved to operate at any desired cutoff frequency (in particular the proposal was evolved from the well-known omnidirectional conical antenna). Thus, two prototypes were built whose gains appeared around $5 \mathrm{dBi}$ for one of the prototypes and $4 \mathrm{dBi}$ for the other one both for a bandwidth of $14 \mathrm{GHz}$. Their front-to-back ratios are equal or less than $-14.9 \mathrm{~dB}$. Moreover, the antenna performance in terms of the magnitude of the reflection coefficient and the radiation pattern converge to an acceptable agreement between measured and simulated results. It is also worth pointing out that an equation that 


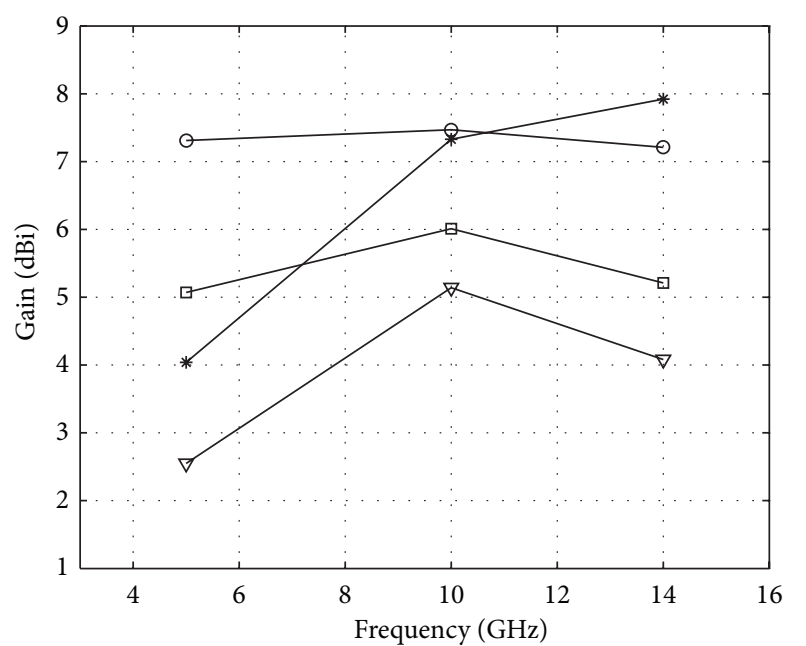

$\square$ Measured gain, prototype 1
- Simulated gain, prototype 1
$\nabla$ Measured gain, prototype 2
$*$ Simulated gain, prototype 2

FIGURE 29: Simulated and measured gain for both proposed planar directional UWB antenna prototypes.

relates the lower cutoff frequency and the radiator length for this type of planar directional antenna was derived. The dissimilarities among lower cutoff frequencies obtained by simulations and measurements and using the resultant equation are less than $10 \%$, which provide us with a realizable form to determine the dimensions of new designs operating at different frequencies. Finally, the radiating element of the antenna has a simple design that reduces cost and weight. The planar directional UWB antenna is suitable for UWB communications systems and other application areas as electronic warfare.

\section{Conflict of Interests}

The authors declare that there is no conflict of interests regarding the publication of this paper.

\section{Acknowledgment}

This work was supported under Projects SEMAR-CONACYT 2003-C02-11873 and CONACYT 127856, Mexico.

\section{References}

[1] A. M. Abbosh and M. E. Bialkowski, "Compact directional antenna for ultra wideband microwave imaging system," Microwave and Optical Technology Letters, vol. 51, no. 12, pp. 28982901, 2009.

[2] S. Qu, J. Li, Q. Xue, and C. H. Chan, "Wideband cavity-backed bowtie antenna with pattern improvement," IEEE Transactions on Antennas and Propagation, vol. 56, no. 12, pp. 3850-3854, 2008.

[3] I. Hertl and M. Strýček, "UWB antennas for ground penetrating radar application," in Proceedings of the 19th International
Conference on Applied Electromagnetics and Communications (ICECom '07), pp. 1-4, September 2007.

[4] J. Yang and A. Kishk, "A novel low-profile compact directional ultra-wideband antenna: the self-grounded Bow-Tie antenna," IEEE Transactions on Antennas and Propagation, vol. 60, no. 3, pp. 1214-1220, 2012.

[5] M. Botello-Pérez, H. Jardón-Aguilar, and I. G. Ruíz, "Design and simulation of a 1 to $14 \mathrm{GHz}$ broadband electromagnetic compatibility DRGH antenna," in Proceedings of the 2nd International Conference on Electrical and Electronics Engineering (ICEEE '05), pp. 118-121, Mexico City, Mexico, September 2005.

[6] M. Ghorbani and A. Khaleghi, "Double ridged horn antenna designs for wideband applications," in Proceedings of the 19th Iranian Conference on Electrical Engineering (ICEE '11), pp. 1-4, Tehran, Iran, May 2011.

[7] M. Kanda, "The effects of resistive loading of "TEM" horns," IEEE Transactions on Electromagnetic Compatibility, vol. 24, no. 2, pp. 245-255, 1982.

[8] K. L. Shlager, G. S. Smith, and J. G. Maloney, "Accurate analysis of TEM horn antennas for pulse radiation," IEEE Transactions on Electromagnetic Compatibility, vol. 38, no. 3, pp. 414-423, 1996.

[9] R. T. Lee and G. S. Smith, "A design study for the basic TEM horn antenna," IEEE Antennas and Propagation Magazine, vol. 46, no. 1, pp. 86-92, 2004.

[10] R. T. Lee and G. S. Smith, "On the characteristic impedance of the TEM horn antenna," IEEE Transactions on Antennas and Propagation, vol. 52, no. 1, pp. 315-318, 2004.

[11] E. Gazit, "Improved design of the Vivaldi antenna," IEE Proceedings H: Microwaves, Antennas and Propagation, vol. 135, no. 2, pp. 89-92, 1988.

[12] L. Tianming, R. Yuping, and N. Zhongxia, "Analysis and design of UWB Vivaldi antenna," in Proceedings of the IEEE International Symposium on Microwave, Antenna, Propagation, and EMC Technologies for Wireless Communications (MAPE '07), pp. 579-581, Hangzhou, China, August 2007.

[13] A. Z. Hood, T. Karacolak, and E. Topsakal, "A small antipodal vivaldi antenna for ultrawide-band applications," IEEE Antennas and Wireless Propagation Letters, vol. 7, pp. 656-660, 2008.

[14] C. Deng and Y. J. Xie, "Design of resistive loading Vivaldi antenna," IEEE Antennas and Wireless Propagation Letters, vol. 8, pp. 240-243, 2009.

[15] G. Adamiuk, R. T. Zwick, and W. Wiesbeck, "Dual-orthogonal polarized vivaldi antenna for ultra wideband applications," in Proceedings of the 17th International Conference on Microwaves, Radar and Wireless Communications (MIKON '08), pp. 1-4, May 2008.

[16] M. John, M. J. Ammann, and P. McEvoy, "UWB Vivaldi antenna based on a spline geometry with frequency band-notch," in Proceedings of the IEEE International Symposium of Antennas and Propagation Society (AP-S '08), pp. 1-4, San Diego, Calif, USA, July 2008.

[17] K. Kota and L. Shafai, "Parametric study of vivaldi antenna," in Proceedings of the 13th International Symposium on Antenna Technology and Applied Electromagnetics and the Canadian Radio Sciences Meeting (ANTEM/URSI '09), pp. 1-4, Toronto, Canada, February 2009.

[18] A. Elsherbini, C. Zhang, S. Lin et al., "UWB antipodal vivaldi antennas with protruded dielectric rods for higher gain, symmetric patterns and minimal phase center variations," in Proceedings of the IEEE International Symposium of Antennas and Propagation, pp. 1973-1976, June 2007. 
[19] H. Schantz, The Art and Science of Ultrawideband Antennas, Artech House, Norwood, Mass, USA, 2005.

[20] H. Wheeler, "The radiansphere sround a small antenna," Proceedings of the IRE, vol. 47, no. 8, pp. 1325-1331, 1959.

[21] S. A. Schelkunoff, Electromagnetic Waves, D. van Nostrand Company, New York, NY, USA, 1943.

[22] C. A. Balanis, Antenna Theory Analysis and Design, WileyInterscience, Hoboken, NJ, USA, 3rd edition, 2005.

[23] G. H. Brown and O. M. Woodward Jr., "Experimentally determined radiation characteristics of conical and triangular antennas," RCA Review, vol. 13, no. 4, pp. 425-452, 1952.

[24] CST Microwave Studio Electromagnetic Field Simulation Software, Computer Simulation Technology, Darmstadt, Germany.

[25] M. A. Peyrot-Solis, G. M. Galvan-Tejada, and H. Jardon-Aguilar, "Directional UWB planar antenna for operation in the 5-20 $\mathrm{GHz}$ band," in Proceedings of the 17th International Zurich Symposium on Electromagnetic Compatibility (EMC '06), pp. 277-280, Singapore, March 2006.

[26] "First Report and Order, Revision of Pa rt 15 of the Commission's Rules Regarding Ultra-Wideband Transmission Systems," Federal Communications Commission, 02-48, April 2002.

[27] M. J. Ammann, "Square planar monopole antenna," in Proceedings of the IEE National Conference on Antennas and Propagation, pp. 37-40, March-April 1999.

[28] N. P. Agrawall, G. Kumar, and K. P. Ray, "Wide-band planar monopole antennas," IEEE Transactions on Antennas and Propagation, vol. 46, no. 2, pp. 294-295, 1998. 

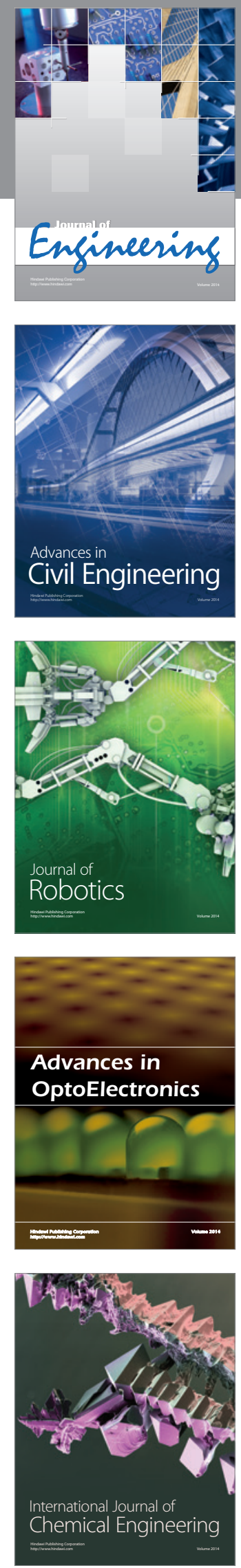

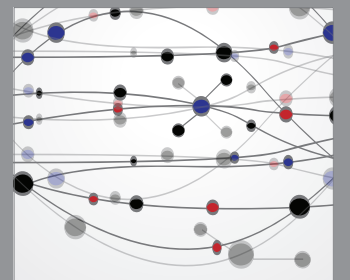

The Scientific World Journal
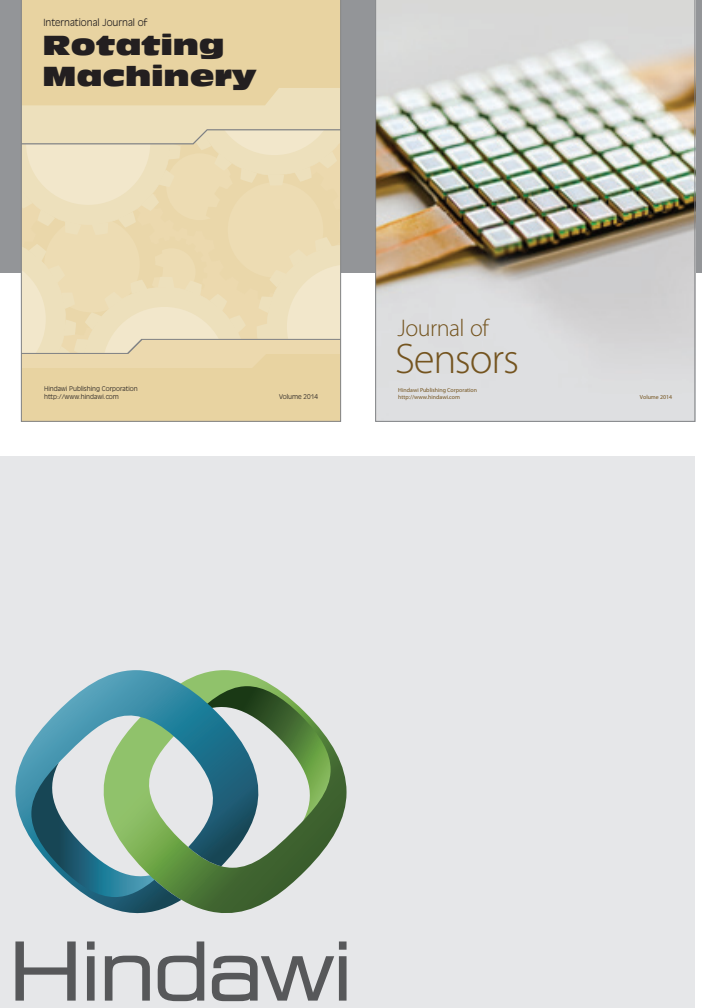

Submit your manuscripts at http://www.hindawi.com
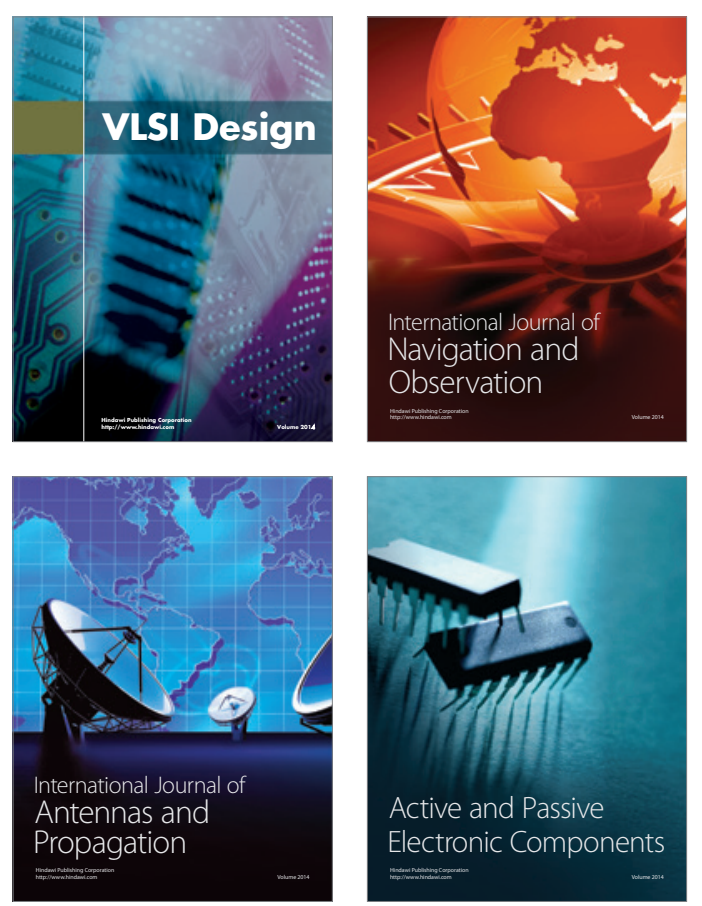
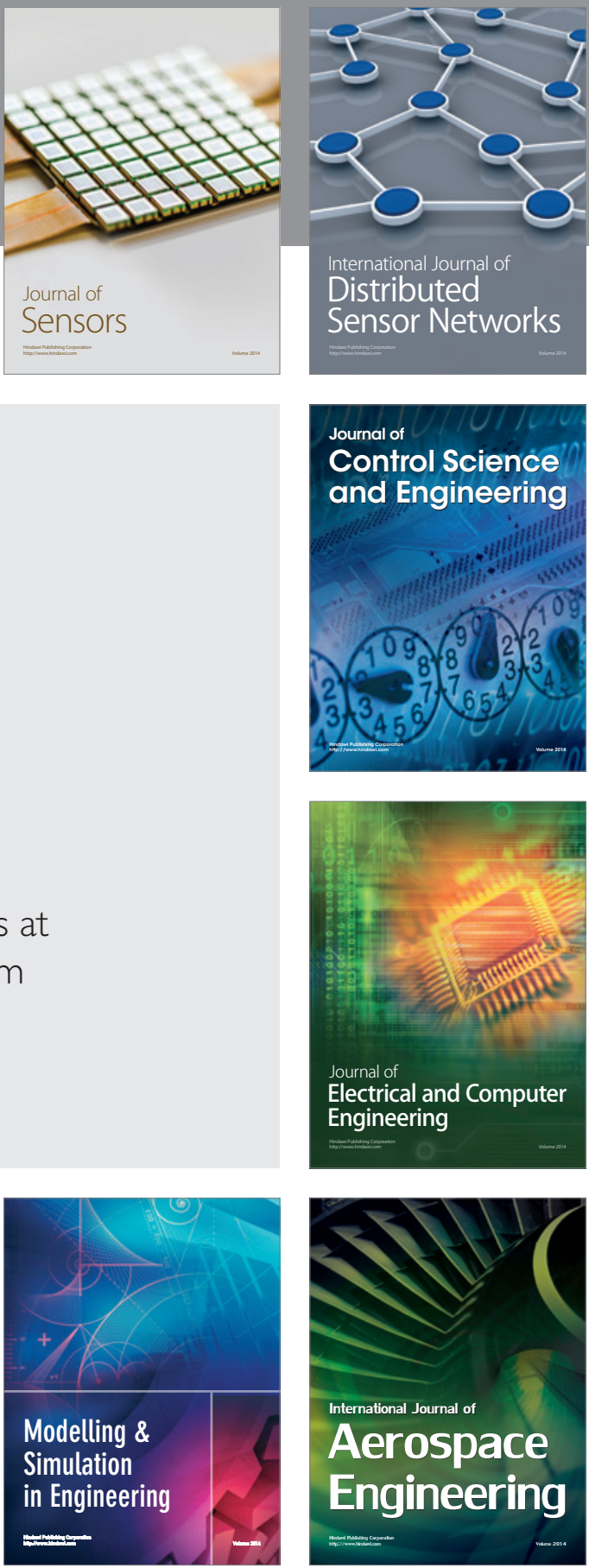

Journal of

Control Science

and Engineering
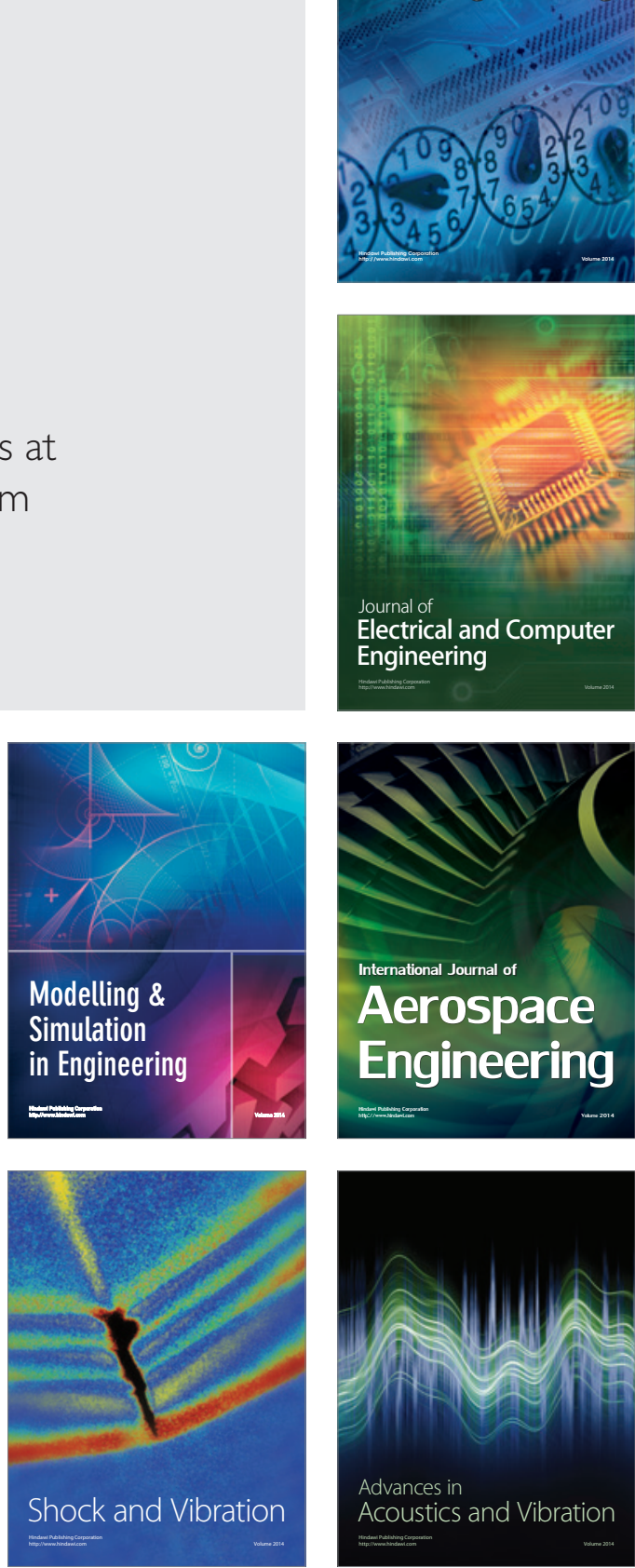